\title{
Subculturas musicales y cultura popular urbana costarricense en los documentales Vargas Brothers y Se prohíbe bailar "suin"
}

\section{Musical subcultures and Costa Rican urban popular culture in the documentaries Vargas Brothers and Se prohibe bailar "suin"}

\author{
Dorde Cuvardic García ${ }^{1}$ \\ Eduardo Cordero Cantillo² \\ Christian Chaves Jaén ${ }^{3}$
}

Fecha de recepción: 06-01-2020

Fecha de aceptación: 22-09-2020

\begin{abstract}
Resumen
La música popular ha ocupado un lugar relevante en la historia del documental. Un grupo numeroso de documentales se ha dedicado a la trayectoria profesional y privada de los músicos, figuras que encaran el desgaste de las giras, de las drogas, etc., mientras que otro grupo enfoca su atención en las prácticas de consumo de la música popular (aficionados, fans). El documental costarricense ofrece manifestaciones de ambas vertientes, en el marco de la modernidad centroamericana: la redención de un grupo de rock and roll, después del viaje a los infiernos de las drogas y el alcohol, en Los Vargas Brothers, y el consumo (baile) de un género considerado marginal por mucho tiempo, el swing criollo, en Se prohíbe bailar suin. La cultura popular urbana costarricense queda representada en ambos documentales.
\end{abstract}

Palabras clave: Rockdocumentary, swing criollo, música centroamericana, rock and roll, identidad popular, identidad urbana

\begin{abstract}
In documentary history, popular music has had a relevant place. A large group of documentaries is dedicated to the professional and private trajectory of musicians, dealing with exhaustion from touring, as well as drug consumption, etc., while another group focuses its attention on the consumption practices of popular music (fans). Costa Rican documentaries show examples from both venues, in the frame of Central American modernity: the redemption of a rock and roll band, after their journey to drugs and alcohol, in Los Vargas Brothers, and the consumption (dance) of a genre considered marginal for a long time, the 'swing criollo', in Se prohíbe bailar suin. Costa Rican urban popular culture is represented in both documentaries.
\end{abstract}

Key words: Rockdocumentary, swing criollo, centroamerican music, rock and roll, popular identity, urban identity

\footnotetext{
1 Doctor en Periodismo y Ciencias de la Comunicación, Especialista en Teoría Literaria, Universidad de Costa Rica, Costa Rica. Correo electrónico: dorde.cuvardic@ucr.ac.cr.

2 Doctor en Tecnología Educativa. Especialista en Tecnología Educativa. Universidad Estatal a Distancia. Costa Rica. Correo electrónico: ecordero@uned.ac.cr

3 Master en Comunicación Digital. Especialista en Comunicación Digital. Universidad Nacional, Costa Rica. Correo electrónico: cristianchjcr@ gmail.com
} 


\section{Introducción}

Desde los años sesenta, el documental ha convertido a la música popular en centro de atención. Esta modalidad discursiva audiovisual puede representar un concierto o recital (en el caso del rock, Woodstock, 1970, dirigido por Michael Wadleigh, sobre este famoso concierto, celebrado en 1969; o Shine a light, 2008, de Martin Scorsese, sobre un concierto de los Rolling Stones). También puede estar dedicado a un género musical (por ejemplo, el hip-hop o el country) o, por último, a la trayectoria de un músico o grupo musical (este último tipo de documental se puede considerar como una modalidad de biopic) ${ }^{4}$. Propuesta fundadora es Don't look back (1967), de D.A. Pennebaker, dedicada a la figura de Bob Dylan. Desde entonces se han producido documentales clásicos, no solo sobre el rock, sino también sobre otros géneros musicales.

En la cultura académica, a escala internacional, los Estudios Culturales, con su legitimación de la cultura popular urbana (muchas veces incorporada a circuitos comerciales) ha asumido las manifestaciones musicales de esta última como objeto de estudio. Por mencionar solo dos ejemplos iniciales de una bibliografía numerosa, Hesmondhalgh (1998) analiza los condicionantes comerciales de la música popular y Dick Hedbidge (2004 [1979]), en un estudio seminal, ha investigado la producción simbólica de la subcultura punk británica de los años setenta ${ }^{5}$. En Costa Rica, si bien el documental ha sido analizado en diversas ocasiones ${ }^{6}$, el de temática musical, que nosotros sepamos, todavía no ha sido investigado, vacío que pretende solucionar el presente artículo, al centrar nuestra atención en Los Vargas Brothers (2012), de Juan Manuel Fernández, y Se prohíbe bailar suin (2003), de Gabriela Hernández. El objetivo del presente artículo consiste en analizar e interpretar ambos documentales desde los procedimientos discursivos audiovisuales que emplean y desde la mirada que expresan en su acercamiento a dos prácticas musicales costarricenses pertenecientes a la cultura popular urbana, una de ellas excluida (el rock) y la otra progresivamente incorporada (el swing) en las políticas culturales gubernamentales.

Los Vargas Brothers y Se prohíbe bailar suin son documentales de observación, si seguimos la propuesta de Bill Nichols (2013, pp. 199-206), también llamado documental directo o de realismo ingenuo. ¿Qué caracteriza a esta modalidad? No hay voz comentarista (voice-over), música o efectos de sonido añadidos en estudio (ambos proceden de la realidad representada), intertítulos o entrevistas propiamente dichas, estructuradas a partir de un guión. Predominan las escenas no dramatizadas, la música surgida del espacio diegético: el discurso y las prácticas de las comunidades son objeto de observación.

Pero Los Vargas Brothers y Se prohíbe bailar suin también son, parcialmente, documentales participativos, si nos ajustamos a la propuesta de Nichols (2013: 207-221). En estos últimos se emplea la observación-participante de un equipo de filmación durante su convivencia con un grupo social (en nuestro caso, un grupo de rock y una comunidad de baile); asimismo, mientras el documental de observación no documenta cómo la presencia del camarógrafo puede alterar una situación dada, el participativo sí visualiza esta alteración. El encuentro entre director y los sujetos sociales configura preguntas éticas sobre esta relación. Vemos cómo actúan uno frente al otro y los niveles de revelación del conocimiento de los sujetos participantes.

4 En este último rubro, Searching for sugar man (2012), documental sueco-británico dirigido por Malik Bendjelloul, cuenta con un mecanismo o idea generadora: ¿por qué un músico que ha fracasado en su natal Estados Unidos -Sixto Rodríguez- es ampliamente reconocido en un país tan lejano -para los estadounidenses- como Sudáfrica? Este documental se estructura, en consecuencia, desde la propuesta argumentativa de la resolución de un enigma.

5 Shohat y Stam (2002), por su parte, desde los estudios poscoloniales, analizan el papel de la música presente en el discurso cinematográfico en la reproducción del eurocentrismo; asimismo, destacan los orígenes orales de la música rap: "en última instancia proviene de los patrones de llamada y respuesta africana y los diálogos que en ciertos espectáculos hay entre intérpretes y público.” (Shohat y Stam, 2002, p. 291).

6 Cuvardic (2011) ha analizado la presencia de procedimientos del falso documental y del documental-ensayo en La región perdida, de Andrés Heidenreich. 
En ambos casos, tanto en The Vargas Brothers como en Se prohíbe bailar suin, los documentalistas han respondido, a través de sus respectivas propuestas, a la pregunta: ¿Cómo representar audiovisualmente a los sectores populares? Como declara Juan Manuel Fernández (en comunicación directa), director del primer documental, sin la propuesta audiovisual que filmó junto con la coparticipación de los hermanos Vargas, "un personaje como Álvaro se hubiera quedado fuera de la Historia (con hache mayúscula), del imaginario costarricense”. Como señala Didi-Huberman (2014), los pueblos se encuentran, más que nunca, expuestos a la representación, pero esto no significa que se encuentren mejor representados. Sin embargo, a través de la coparticipación en el proceso de producción de ambos documentales, los sujetos representados en The Vargas Brothers y en Se prohíbe bailar suin se convirtieron en sujetos enunciadores que se aseguraron una representación pública legítima de su sistema de valores culturales.

Las subculturas musicales representadas en ambos documentales pertenecen a dos experiencias bien delimitadas, en términos socio-musicales: la experiencia del concierto de rock en vivo, y la experiencia del baile. La cultura popular visualizada en ambos documentales es urbana: son prácticas musicales a través de las que se forman comunidades de seguidores, a través de las que se supera la anomia, la experiencia disgregadora de la ciudad latinoamericana contemporánea. En ambos casos se produce un consumo alejado de las coordenadas sociales, económicas y tecnológicas de la música integrada en la industria cultural. Pero al mismo tiempo se trata de prácticas que no hubieran surgido si al mismo tiempo no se hubieran desligado en cierto momento de una industria musical que busca apelar a la masa urbana.

Los Estudios Culturales tienen un propósito bien preciso cuando adoptan la cultura popular (y en particular la musical) como objeto de estudio: "La música popular importa, en esta corriente, por su destacada posición en los procesos de articulación de identidades nacionales, de etnia, clase, género y sexualidad y, en definitiva, como formas de enunciación política, social y cultural." (García-Peinazo, 2019, p. 46). En este sentido, la práctica documentalista, a través de sus propuestas discursivas, problematiza una definición esencialista de la identidad nacional y de la cultura popular. El documental puede expresar y al mismo tiempo promover novedosas políticas identitarias. Los Vargas Brothers articula la identidad urbana popular con problemáticas de clase y desclasamiento, mientras que Se prohíbe bailar suin, además de representar el vínculo entre música, baile y clase social, también articula esta expresión cultural con el género y la sexualidad.

Martín-Barbero (2002, p. 54) destaca que "[n]o podemos pensar lo popular actuante al margen del proceso histórico de constitución de las masas: de su acceso a la visibilidad social y de la masificación en que históricamente ese proceso de materializa." (en cursiva en el original) (véase, asimismo, Martín-Barbero, 1987). Tanto el 'cover'7 del repertorio de Los Vargas Brothers como el baile de salón del swing no representan prácticas promovidas por la industria musical; sin embargo, son prácticas dependientes de los medios de comunicación de masas. Se vinculan, en este sentido, con lo masivo. Sin la programación de las radios en inglés que emiten en FM en el Valle Central no se podría haber dado la práctica del 'cover', mientras que, sin la programación regular de la cumbia en las radios en español no se hubiera popularizado el swing.

\section{Viaje a los infiernos y redención de un grupo de rock en Los Vargas Brothers: la cultura obrera en los barrios del Sur}

Los Vargas Brothers (2012) es un largometraje documental dirigido y escrito por Juan Manuel Fernández. Es un ejemplo de lo que se conoce como rockumentales. El tema que guía su estructura no es, en todo caso, el retrato de un género musical (el rock), ni el registro de un concierto o de una gira emblemática de un artista o de un grupo, sino la historia personal de una banda formada por cuatro hermanos: Álvaro Vargas (guitarra eléctrica), Eddy Vargas (bajo y voz), Juan Vargas (batería) y Eduardo Vargas (voz principal). En este sentido, es un biopic colectivo, es decir, nos ofrece una biografía profesional de un grupo de hermanos -visualizado por el afiche oficial de la película-

$7 \quad$ El 'cover' es una versión de un tema musical realizada por un cantautor o grupo distinto al que lo ha compuesto o cantado inicialmente. 
que el director del documental llegó a conocer cuando un amigo suyo, Julio Acuña, le llevó a uno de sus conciertos.

Los Vargas Brothers es, junto con Los vikingos, una de las primeras bandas de rock surgidas en Costa Rica, estilo musical que encontró su máxima difusión nacional en los años ochenta a través de grupos como Café con leche o 50 al Norte. Su repertorio ha consistido, desde su creación, en 'covers' en español e inglés. Sin conocimiento de este último idioma, este grupo de hermanos cantaba las letras de grupos estadounidenses y británicos, según su propia percepción intuitiva de lo que debería ser la pronunciación del inglés. Nacidos en San Ramón de Alajuela, pasaron su infancia en Alajuelita, uno de los llamados barrios del Sur, que alberga sectores obreros, populares y marginales del Gran Área Metropolitana de San José.

A raíz de un concurso, en 1978 fueron elegidos para abrir como teloneros un concierto que ofreció Santana en el país. Juan Manuel Fernández (en comunicación personal) señala que su participación en este acontecimiento, el clímax en la carrera de este grupo, no recibió ni una sola mención en la prensa nacional. De alguna manera, asumieron su participación en el documental de Fernández como reivindicación, largamente diferida, de su carrera profesional. En otras palabras, Los Vargas Brothers fue considerado por este grupo de hermanos como la gloria o fama final que no pudieron alcanzar en su momento a través de los medios de comunicación. En sus inicios tocaban, como señala el director (en comunicación personal), en cines como Líbano, a partir de contribuciones voluntarias.

La historia pública y privada de este grupo de hermanos, tal como la ofrece este documental, es el símbolo representativo (sinécdoque) de una Costa Rica -situada en los años setenta y ochenta- marginal, obrera, de trabajo informal, que sobrevivía en el día a día. Uno de los integrantes del grupo, Eddy Vargas, en particular, llegó a dormir en el informalmente llamado 'Parque de las cacas', situado detrás del céntrico Hospital San Juan de Dios. Como recuerda el director (en comunicación personal), al llegar con Eddy para realizar la filmación de una escena, este último fue reconocido por uno de los mendigos del parque. Si algo destaca el documental es el esfuerzo titánico de este grupo de hermanos por sobrevivir y superar las más duras condiciones económicas y psicológicas ante la tragedia de las drogas y el alcoholismo y por reivindicarse como artistas de pleno derecho, ante una sociedad y una cultura establecida que les dio la espalda. Zúñiga (2004) alude a la 'Otredad optada' de los miembros de la subcultura juvenil del rock costarricense, deseosos de convertirse en Otredad para una sociedad normativa que repudian. En esta visión de mundo podemos situar a Los Vargas Brothers.

El documental, filmado entre el 2007 y el 2012, está estructurado en un prólogo y en tres partes claramente diferenciadas. El preámbulo lo ofrece el proyecto que tienen los integrantes de este grupo musical de organizar y celebrar su 44 aniversario en el Salón Bella Vista (situado en San Francisco de Tres Ríos) y en otras localidades, en las que tradicionalmente habían tocado sus conciertos (se plantea, entre otras actividades, la búsqueda de patrocinadores, etc.). La primera parte está dedicada a presentar la cotidianeidad contemporánea (es un documental filmado en el 2010 y estrenado en el $2012^{8}$ ) de cada uno de los hermanos. Se presenta su día a día, desde una semántica iterativa: se parte del supuesto de que las imágenes singulares ofrecidas representan su cotidianeidad, próxima a una sobrevivencia llena de penalidades económicas, en los barrios socialmente 'degradados' del sur de San José. La segunda parte, en cambio, está dedicada a indagar, desde los recuerdos actuales de cada uno de sus integrantes, la época de 'éxito' local -es decir, circunscrita a San José- de este grupo, ubicada en los años setenta y los primeros años ochenta. La tercera parte, que consideramos como la más lograda, retrata desde una perspectiva retrospectiva, y desde la propia voz de sus protagonistas, la 'caída' en las drogas y el alcohol de cada uno de sus integrantes y su posterior redención (son 'cápsulas' dentro del documental, con su

8 En julio del 2012 Los Vargas Brothers fue estrenado en el Cine Variedades. En noviembre del mismo año se estrenó en seis cines de San José, en salas del Mall San Pedro, en Multiplaza Escazú, en San Ramón, en el Cine Variedades, en Cinépolis Terramall y en el Mall de Desamparados. 
respectivo inicio y cierre). De hecho, en momentos en los que Juan Manuel Fernández filma a estos hermanos, es decir, en el presente de la enunciación fílmica, se encuentran en pleno proceso de recuperación o salida del 'infierno' de la adicción a las drogas. En este sentido, se centra en la vida privada de personajes públicos, conocidos como músicos. Junto con el director del documental, los integrantes de este grupo realizan un viaje para buscar los sitios en los que habían vivido y en los que habían tocado.

El mecanismo narrativo inicial del documental queda asociado a la búsqueda de patrocinadores que financien el mencionado aniversario. Las conmemoraciones, homenajes o aniversarios se convierten en la situación generativa -el punto de partida inicial- de muchos documentales y películas de ficción que tienen por protagonistas a artistas o intelectuales. Este motivo generativo consiste en que un grupo o un cantante celebre un aniversario, un escritor sea objeto de un premio o un académico reciba un homenaje de sus colegas en el momento de su retiro9. La parte central de estas historias tiene carácter retrospectivo: los artistas, los escritores o los académicos recuerdan su vida, sus logros y fracasos. Al final de estos documentales y películas de ficción, se regresa al presente de la enunciación, cuando se celebra el concierto conmemorativo, la premiación, el homenaje o el aniversario. La estructura narrativa, en todos estos casos, se identifica con claridad. En el caso de The Vargas Brothers, se inicia con la intención de los músicos de organizar un concierto-homenaje, seguidamente se ofrece la etapa de éxito, la caída en las drogas y el alcoholismo y la posterior redención. Como epílogo, se termina con la realización del concierto homenaje en el Salón Bella Vista.

Los Vargas Brothers relata una tragedia familiar. Recordemos, junto con Aristóteles, tal como destaca en la Poética, que la tragedia se ceba muchas veces en el seno de las familias. En la vida contemporánea nos referimos a las 'pequeñas' tragedias cotidianas, en las que potencialmente podría caer cualquier persona. Se operan dos giros dramáticos, en el marco de la estructura narrativa implícita de este documental. En primer lugar, la caída en el 'infierno' de las drogas y el alcoholismo de este grupo de hermanos y, en segundo lugar, su recuperación psicológica y anímica y su precaria reinserción social y laboral.

Para este grupo de hermanos, no sólo la música -el arteofrece la redención para el ser humano, y dentro de esta última la celebración del concierto homenaje. También cumple este propósito la religión (la evangélica, en este caso), la familia y, cómo no, este mismo documental, que contribuye a recuperar la memoria de este grupo musical en la conciencia del costarricense, que disfrutó de su música en la etapa de su 'esplendor'. La música no sólo supone la causa indirecta de la 'caída' en las drogas y el alcohol de este grupo, sino que también se convierte en uno de los mecanismos que impulsan su redención.

\section{Se prohíbe bailar suin: una comunidad de baile en Costa Rica}

Se prohíbe bailar suin (2003) es un mediometraje de Gabriela Hernández que obtuvo el premio al Mejor Documental, el premio del Público y la mención al Mejor Sonido en la XII Muestra de Cine y Video Costarricense (noviembre del 2003). Como señala la directora, la grabación duró 12 días, repartida en más de dos meses. Previamente, la preproducción se había prolongado por tres años, dedicada, entre otras actividades, a buscar financiamiento, obtenido, en la etapa inicial de filmación, a través de la AECID (Agencia Española de Cooperación Internacional para el Desarrollo). Esta producción no es la única que Gabriela Hernández ha consagrado a la cultura popular: cuenta con 12 cortos documentales (Vamos al matiné, Vamos a Ojo de agua, Vamos a bailar, entre otros) sobre espacios y prácticas de recreación de la cultura popular -muchas de ellas urbanas- en trance de desaparición y cambio.

Ante todo, definamos el tema de este documental. ¿Qué es el swing criollo [suin, en transcripción escrita de la pronunciación fonética de esta palabra]? Es un baile que gira alrededor de la cumbia colombiana como género musical. En su origen se incorporaron recursos propios para bailar el swing de las grandes bandas estadounidenses; estos pasos de baile se consolidaron en los 
sectores populares de la Meseta Central y, reinterpretados, pasaron a formar parte de una nueva modalidad de baile que tomó la cumbia como base musical (Valle Cedeño, 2015, p. 92). Pero, como señala Gabriela Hernández (en comunicación personal), el enfoque o concepto implícito que empleó en su documental consistió en mostrar que el swing criollo es, más que una forma de baile, una cultura, con sus espacios, dinámicas, estéticas y visión de mundo particular. Y, como toda cultura o comunidad, está llena de rituales. Uno de los más llamativos es el del traje. La vestimenta empleada por las y los bailarines es holgada y de tonos brillantes. Pero si algo particulariza al swing criollo son los pasos de baile ejecutados por sus bailarines, en constante transformación a través de los años:

El principio técnico que rige la utilización del cuerpo es el rebote constante, que amortigua los acentos del peso del cuerpo al marcar el pulso musical. Es una característica específica la introducción de pequeños saltos. El uso del peso ha variado bailándose con una leve acentuación hacia arriba del año 95 (aproximadamente) para atrás y agregando posteriormente la utilización de pasos de mayor peso a tierra. (Valle Cedeño, 2015, p. 95).

La cultura hegemónica se encargó, desde un inicio, de estigmatizar en sus discursos la cultura del swing, popularizada en los barrios del centro de San José y en los municipios del Gran Área Metropolitana. En el documental, Carlos Morera Alfaro, alias "Gringo", afirma que, en algunos lugares, se colgaban carteles con el acto de habla directivo "Se prohíbe bailar suin", como ocurrió en los salones de baile El gran parqueo y Aloa, o según Chaves (2007, p. 141), en El Jocote, de San Joaquín de Flores. Recordemos, en este sentido, que a lo largo de la historia occidental distintos géneros musicales han sido objeto, desde la ideología hegemónica, de campañas de repudio, en el marco de la llamada alarma social o pánico moral dirigido contra diversas subculturales, muchas de ellas organizadas a través de la música. Así ocurrió en su momento con el jazz, con el rock and roll ${ }^{10} \mathrm{o}$ con la música disco. El título del mediometraje pretende destacar los prejuicios y la actitud elitista que la ideología hegemónica ha tenido hacia las manifestaciones de la cultura popular urbana.

Diversos son los salones de baile y las discotecas que ofrecían y todavía ofrecen espacios para bailar el swing criollo. Es el caso de Karymar -la antigua Ipanema-, en el municipio de Guadalupe; de Montecarlo, también conocido como el "Infiernillo", en Zapote; o de Mi oficina (convertido en billar en el momento de la filmación del documental), en el centro de San José. También destacaron en los años setenta y ochenta las discotecas y salones de baile O.K., $E l$ bambú, Cañaveral, El séptimo cielo, La Sodita del Valle, El Pirros y El Herediano. A inicios del milenio, como señala Valle Cedeño (2015, p. 93) seguían abiertos espacios como Los Bozales, Los Barriles, El Tania o El Típico Latino.

Frente a su marginalidad inicial (desde el punto de vista de la cultura hegemónica), el swing criollo ha sido objeto, en la última década, de estrategias legitimadoras por parte de la institucionalidad cultural. En este sentido, Laura Chinchilla, en aquel entonces presidenta de la República, firmó el 3 de mayo del 2012 el decreto -publicado en $L a$ Gaceta (n. 85, Alcance n. 57, decreto n. 37086C)- para declarar al swing criollo como expresión dancística del patrimonio cultural inmaterial de Costa Rica (Valle Cedeño, 2015, p. 93). El éxito del documental de Gabriela Hernández fue crucial en esta declaratoria. Es un ejemplo que nos demuestra la capacidad que tiene el audiovisual - y en particular el documental- para fomentar y transformar las políticas culturales de un Estado-nación.

Su directora, por lo demás, ha sido invitada a universidades de Estados Unidos (Tulane, Texas; Carolina del Norte; Duke University) y, en el marco de las acciones encaminadas a preservar la vigencia de esta manifestación cultural, ha presentado Se prohíbe bailar swuin en diversas comunidades de Costa Rica (Barrial de Heredia; Barva de Heredia; El Cedral, San Pedro de Montes de Oca). En el ámbito de la gestión y promoción cultural, así como en la popularización ciudadana de este baile y en su presencia en la imagen turística del país, se han dado grandes pasos desde los años noventa.

$10 \quad$ Hedbige (2004 [1979]), en este sentido, analiza el pánico moral creado alrededor de los mods, los skin heads y los punk a finales de los años setenta. 
Valle Cedeño (2015, p. 93) menciona algunos de ellos: su integración en el espectáculo de baile popular Echémonos a pista (coreografía de Liliana Valle, 1991), en puestas en escena de grupos de proyección del folclore como Fantasía Folclórica, 1991, de Luis Carlos Vázquez y Nandayure Harley, así como su incorporación en espectáculos turísticos (Hotel Playa Tambor, Hotel Fiesta). Ligia Torijano ha sido una de sus grandes promotoras en los últimos treinta años. En los años noventa comenzó a ofrecer clases en dos salones de Guadalupe, Karymar (en donde se filmaron la mayor parte de las escenas de Se prohíbe bailar swing), y Barriles Discoteque, así como en la academia de baile Merecumbé. Asimismo, ha producido espectáculos, como es el caso de Permiso... viene el swing ${ }^{11}$.

No solo el mediometraje de Hernández ha analizado esta subcultura de baile, sino también la academia, con una tesis de antropología defendida en la Universidad de Costa Rica en el 2012, posteriormente publicada como libro, titulado este último Brincos y vueltas a ritmo de swing. Explorando las experiencias corporales y simbólicas de esta práctica cultural costarricense (2014), de Claudia López Oviedo y Paola Salazar Arce. Pero recordemos que, asimismo, los propios practicantes de este baile realizan un importante trabajo de investigación y preservación cultural del swing criollo.

Se prohíbe bailar suin es, predominantemente, un documental de observación. La cámara observa y sigue a los aficionados mientras bailan y, además, los acompaña en su vida cotidiana. Por su parte, la modalidad del documental interactivo domina en aquellos momentos en los que los participantes de esta comunidad de baile se dirigen a la cámara y hacen, por ejemplo, demostraciones ante el objetivo: bailan porque han sido citados en un salón para que ejecuten los pasos delante de las cámaras. En estos momentos se revela, en el visionado del documental, la presencia de la cámara y los encuentros entre los bailarines y el equipo de producción de la película. Se muestra, en consecuencia, un encuentro de subjetividades. En particular, en Se prohíbe bailar suin se emplea la técnica de la masked interview o encuentro preparado, donde se acuerda con los sujetos retratados las conductas que se filman y los tópicos de los que hablan sus protagonistas. En el documental son los propios bailarines los que presentan y explican al espectador los escenarios y la cultura del swing. Muestran la ubicación de las discotecas y salones de baile, algunos de ellos situados en la llamada zona 'roja' de San José, unos cerrados y otros transformados en negocios de diverso tipo. Gabriela Hernández puso en práctica un procedimiento discursivo que, como señaló en una oportunidad en una entrevista, debería incorporarse en todo documental dedicado a representar el patrimonio cultural inmaterial:

Para mí resulta más convincente si en lugar de un experto o de un narrador es la misma gente en sus entornos, los mismos hacedores o protagonistas de esos procesos, quienes toman la palabra o se desenvuelven frente a la cámara. El registro de testimonios es todo un arte también: el lugar donde se ubique la persona mientras relata, lo que sucede o se ve al fondo, si se encuentra aislado o lo acompañan otros participantes. Hay técnicas para animar una conversación o un debate entre informantes. (Hernández, 2020)

El afiche promocional del documental transmite la semántica de los salones de baile de barrio en Costa Rica: las paredes de estos lugares no están repelladas y los bloques de cemento se encuentran pintados, muchos de ellos de verde, color asociado a las paredes exteriores y los muros de los barrios 'pobres' del Valle Central. El primer plano del documental, después de los títulos de crédito, es una vista panorámica de San José. Nos indica que el espectador se acercará a una realidad y a una práctica cultural estrictamente urbana. Entre los sujetos entrevistados, José Manuel Quirós Porras afirma que los obreros, los taxistas y las prostitutas tenían una gran afición al swing, mientras que Elías Elizondo Solera explica que la 'chusma' es la afición que le da vida a esta

11 Además, ha promovido ha promovido el swing tanto a nivel nacional (FIA, FNA, TRANSITARTE, Puntos de Cultura, Proartes, Teatro al Mediodía en el Teatro Nacional, Teatro Melico Salazar, Auditorio Nacional, Parque Nacional) como internacional, en 13 países de 3 continentes (Feria ITB de Berlín, Feria FITUR, de España). 
comunidad de baile. Como sucede con toda manifestación cultural popular, deviene finalmente en objeto de estudio; igualmente, terminó por incorporarse en los programas de baile institucionalizados, entre ellos el de la Compañía Nacional de Teatro (López Oviedo y Salazar Arce, 2012, p. 57).

Este documental quiere mostrar el amplio espectro social aficionado al swing, frente al pretendido escaso apoyo que tendría, estereotipo o cliché posiblemente originado en la clase media costarricense. Entre los sujetos entrevistados se encuentran Carlos Morera Alfaro, alias "Gringo", ganador de concursos de baile y prestamista; Ligia Torijano, investigadora del swing; Elías Elizondo Solera, taxista; Francisco Tristán, fundador del grupo Taboga y profesor de la Escuela de Odontología de la Universidad de Costa Rica; José Manuel Quirós Porras, disk jockey en el salón de baile Karymar; y Daniel Hernández Solano, alias Tito, profesor y bailarín, que cose los trajes de gala y organiza grupos coreográficos, tal como se muestra en el documental. Personas de todos los estratos sociales se ‘confiesan’ aficionados y ‘fanáticos’ de este baile.

Algunos de ellos comenzaron a practicarlo después de pasar por otros tipos de bailes y relatan el progresivo hechizo que les produjo. Como ocurre en toda subcultura, se organiza una distinción identitaria interna. Algunos bailarines destacan su condición de bailarines de la 'vieja guardia', frente a los bailarines que practican suin desde época más reciente (Véanse las percepciones y las autopercepciones de los bailarines del suin ante la 'vieja' y la 'nueva' guardia en López Oviedo y Salazar Arde, 2012, pp. 85-102).

El swing tiene la particularidad de ser también un baile de pareja e, incluso, grupal. Adopta implicaciones machistas, ya que un bailarín puede encargarse de bailar y de 'controlar' a varias bailarinas. López Oviedo y Salazar Arce (2012, p. 67) explican que "cabe la posibilidad de ver tríos compuestos de dos hombres y una mujer, en el cual se van alternando la batuta y dirección del trío al momento de ejecutar los pasos y movimientos." Se han visto, asimismo, grupos mayores. El baile es el protagonista del documental y, por tal motivo, se dedican los últimos minutos a mostrar parejas que lo practican. Este documental inicia con entrevistas donde los protagonistas hablan del swing y termina su metraje mostrando cómo lo practican. Lo mismo ocurre en The Vargas Brothers, que inicia con la organización de un concierto homenaje que después tendrá lugar. La performatividad se convierte en un clásico cierre de los documentales de temática musical.

El concepto de comunidad, y más exactamente, el de comunidad musical y de baile como comunidad de estilo, acerca a Se prohíbe bailar suin a documentales como Trekkies (1997), de Roger Nygard, que indaga en toda la creatividad estilística de la comunidad de fans de Star Trek, y a un libro como Subcultura. El significado del estilo (1979), donde Dick Hebdige reflexiona sobre la música punky las prácticas culturales de esta comunidad. Aunque la clase media también forma parte de los aficionados a este baile, Se prohíbe bailar suin es un documental en el que la estructura argumentativa principal procede del sujeto subalterno, de aquellos trabajadores urbanos que, en su tiempo de ocio, se dedican a este baile.

A su vez, este documental no sólo representó, desde un punto de vista antropológico, las prácticas de baile de una subcultura musical, sino que, asimismo, tuvo consecuencias o efectos pragmáticos en la sociedad costarricense. Como destaca su directora, Gabriela Hernández (en comunicación personal): "El documental definitivamente contribuyó a catapultar el swing criollo en el país, y algunos de sus participantes lograron hasta dedicarse por completo a las clases y a la difusión del género a partir del reconocimiento que hizo la película de su talento y su aporte."

\section{Conclusiones}

Los dos documentales costarricenses analizados privilegian la performance musical. En The Vargas Brothers, este grupo de hermanos ejecuta 'covers', es decir, reinterpretan los clásicos del rock. En Se prohíbe bailar suin se destaca, más bien, la comunidad de baile formada a partir del género musical de la cumbia. Asimismo, las escenas finales de ambos documentales destacan la música como performatividad. En The Vargas Brothers se ofrecen imágenes del concierto del 44 aniversario de 
este grupo, mientras que en Se prohíbe bailar suin se muestra a los participantes, a la comunidad retratada a lo largo del documental, en la pista de baile.

Existen similitudes y diferencias entre ambos documentales. Entre las similitudes se encuentra el hecho de que ambos visibilizan formas musicales transculturales. En el caso de Se prohíbe bailar suin, hablamos de la música de la cumbia, fusionada con un ritmo de baile originado en las grandes bandas estadounidenses; en el caso de The Vargas Brothers hablamos de 'covers' en inglés -desde la cultura costarricense urbana-, es decir, de éxitos del rock anglosajón.

Gabriela Hernández y Juan Manuel Fernández buscan legitimar el valor musical de los géneros que protagonizan sus respectivos documentales. El tema de Se prohíbe bailar suin es el baile y un género musical, la cumbia. Se busca que sean los propios protagonistas quienes ofrezcan, en tono didáctico, a audiencias no conocedoras, en qué consiste la comunidad swing. A su vez, el 'cover' queda dignificado en The Vargas Brothers. En todo caso, ocupa un papel secundario en este último documental. El principal interés es ofrecer un documental biográfico. Salvando las distancias, se pueden establecer puentes comparativos (buscando similitudes y contrastes) con otros documentales biográficos familiares del mundo de las artes o de las letras, como El desencanto (1976), de Jaime Chávarri, sobre las conflictivas relaciones entre los distintos miembros de la familia de escritores de los Panero (Juan Luis Panero, 'Michi' Panero y Leopoldo María Panero).

En la sociedad latinoamericana contemporánea el baile ocupa un lugar más relevante que en otras culturas. ¿En qué medida estos dos documentales expresan o singularizan problemáticas identitarias de la región centroamericana? En The Vargas Brothers se tematiza la intervención de la cultura de masas estadounidense en la construcción de la cultura popular urbana de la región, mientras que en Se prohíbe bailar suin se representa la transculturación de la cultura musical latinoamericana con la norteamericana. El propio uso del término suin, en lugar de swing, nos habla de la apropiación criolla, latinoamericana, popular, de una práctica de baile de origen estadounidense y, en estos términos, de un fenómeno de transculturación.

\section{Bibliografía}

Chaves, B. (2007). Lo que se baila en Costa Rica: análisis musical de una cumbia costarricense. Herencia, 20 (1 y 2), pp. 137-146.

Cuvardic García, D. (2011). Un género postmoderno en la producción cinematográfica costarricense: el filme-ensayo en La región perdida. Revista Comunicación, 20 (2), pp. 74-82.

Didi-Huberman, G. (2014). Pueblos expuestos, pueblos figurantes. Buenos Aires: Editorial Manantial.

García-Peinazo, D. (2019). El análisis musical y los estudios sobre música popular urbana: de la doble negación a la educación en las discrepancias participatorias. Revista internacional de educación musical, 7, pp. 45-54.

Hebdige, D. (2004 [1979]). Subcultura. El significado del estilo. Barcelona: Paidós.

Hernández, G. (2004). “'Por qué el swing criollo?”. Revista virtual Istmo, 9, http://istmo.denison.edu/nog/ articulos/suin.html (recuperado el 9 de abril del 2019).

López, C.; Salazar, P. (2010). Brincos y vueltas a ritmo de swing: un análisis antropológico de la práctica del swing criollo, a partir de las representaciones sociales que bailarines y bailarinas configuran respecto a este fenómeno dancístico. Tesis para optar por el grado de Licenciatura en Antropología Social, Universidad de Costa Rica. San José, Costa Rica.

López, C.; Salazar, P. (2014). Brincos y vueltas a ritmo de swing. Explorando las experiencias corporales y simbólicas de esta práctica cultural costarricense. Saarbrüken, Alemania: Editorial Académica Española. 
Martín-Barbero, J. (1987). De los medios a las mediaciones. Comunicación, cultura y hegemonía. Barcelona: Gustavo Gili.

Martín-Barbero, J. (2002). Culturas populares. En: Carlos Altamirano (Comp.). Términos críticos de sociología de la cultura. Buenos Aires: Paidós, 49-6o.

Nichols, B. (2013). Introducción al documental. México: Centro Universitario de Estudios Centroamericanos (Universidad Nacional Autónoma de México).

Shohat, E. y Stam, R. (2002). Multiculturalismo, cine y medios de comunicación. Crítica del pensamiento eurocéntrico. Barcelona: Paidós.

Valle Cedeño, Liliana. (2015). Apuntes sobre el baile popular en Costa Rica. Revista Ístmica, 18, pp.7398.

Zúñiga, M. (2004). 'Ahora que somos otros: Notas en torno a la 'Otredad optada' y al rock juvenil costarricense, Cuadernos de Antropología, 14, 95-106.

\section{Filmografía}

Se prohíbe bailar suin. Dirección: Gabriela Hernández. 2003. Documental. LaTica de Película Producciones.

The Vargas Brothers. Dirección: Juan Manuel Fernández. 2012. BioFilms Producciones.

\section{Entrevista}

Fernández, J. M. (2020). Entrevista sobre el swing [Entrevista personal por WhatsApp]. San José.

Hernández, G. (2020). Entrevista sobre el swing [Entrevista personal por WhatsApp]. San José.

Torijano, L. (2020). Entrevista sobre el swing [Entrevista personal por WhatsApp]. San José. 


\section{Anexos}
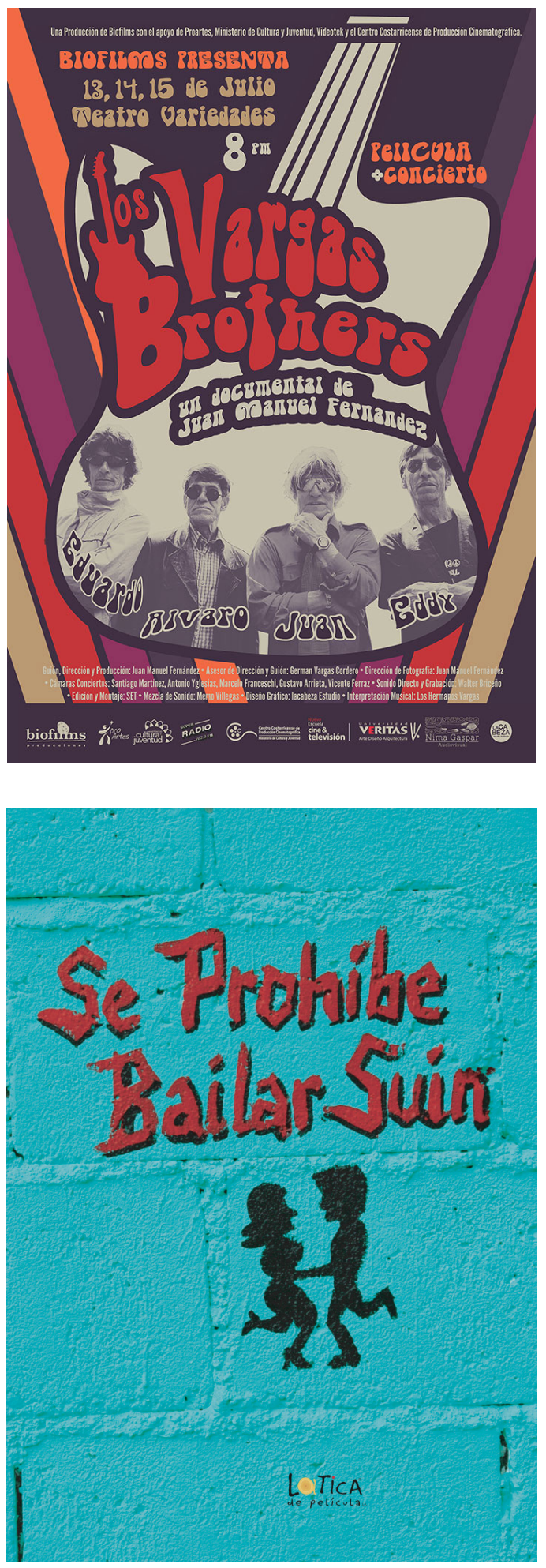